\section{Hemoglobinas variantes em doadores de sangue do Centro de Hematologia e Hemoterapia do Estado do Piauí (Hemopi): Conhecendo o perfil epidemiológico para construir a rede de assistência}

Hemoglobin S variants in blood donors of the
Hematology and Hemotherapy Center of the
state of Piauí (Hemopi): Understanding the
epidemiological profile to create a support
network

Leonardo F. Soares

Evaldo H. Oliveira ${ }^{2}$

Iraildo B. Lima ${ }^{3}$

José M. Silva ${ }^{4}$

Jônathas T. Mota

Claudia R. Bonini-Domingos ${ }^{6}$

${ }^{1}$ Farmacêutico bioquímico. Prof. da Disciplina Hematologia Clínica do Curso de Farmácia da Universidade Federal do Piaui- UFPI.

${ }^{2}$ Farmacêutico bioquímico. Prof. da Disciplina Imunologia Clínica do Curso de Farmácia da Universidade Federal do Piaui- UFPI

${ }^{3}$ Farmacêutico bioquímico - Hemopi

${ }^{4}$ Farmacêutico bioquímico.

${ }^{5}$ Aluno do Curso de Farmácia da Universidade Federal do Piauí UFPI.

${ }^{6}$ Bióloga. Profa. responsável pelo Laboratório de Hemoglobinas e Genética das Doenças Hematológicas (LHGDH) - IBilce - Unesp.

\section{Sr. Editor}

Considerada a afecção genética de maior prevalência mundial, a anemia falciforme possui uma elevada frequência em países africanos. O gene da hemoglobina $\mathrm{S}$ tem alta frequência em toda a América, e no Brasil é mais frequente nas regiões sudeste e nordeste, observando-se uma distribuição heterogênea, sendo esta doença considerada um problema de saúde pública. ${ }^{1}$ Estudos epidemiológicos sobre a doença falciforme no Brasil são restritos a algumas regiões; até meados dos anos 90 não existia qualquer programa oficial de saúde pública voltado para aqueles indivíduos com anemia falciforme. ${ }^{2}$ Consolidando uma fase de iniciativas dos movimentos sociais e da academia, em 16 de agosto de 2005 foi publicada a Portaria de $\mathrm{n}^{0} 1.391$, que institui no âmbito do SUS as diretrizes para a Política Nacional de Atenção Integral às Pessoas com Doença Falciforme e outras Hemoglobinopatias. $^{3}$

Indivíduos que apresentam a hemoglobina $\mathrm{S}$ em homozigose (SS) evidenciam uma condição grave da doença, enquanto indivíduos com a hemoglobina $\mathrm{S}$ em heterozigose (AS) não apresentam manifestações clínicas, não conferindo qualquer risco ao seu portador. ${ }^{4,5,6}$

A Organização Mundial da Saúde estima em aproximadamente 270 milhões de pessoas com hemoglobinas variantes. $\mathrm{Na}$ África Equatorial, $40 \%$ da população é portadora do gene em heterozigose, já a doença atinge uma prevalência de $2 \%$ a $3 \%$. No Brasil, a anemia falciforme acomete de $0,1 \%$ a $0,3 \%$ da população negra, com tendência a atingir parcela cada vez mais significativa da população, devido ao alto grau de miscigenação em nosso país. De fato, estudos populacionais têm demonstrado a crescente presença de hemoglobina $\mathrm{S}$ em indivíduos caucasoides.?

No estado do Piauí, em pesquisa realizada entre os estudantes do curso de Farmácia da Universidade Federal do Piauí (UFPI), foi constada a prevalência de 3,0\% do traço falciforme. Estudos realizados em três comunidades quilombolas na região de Paulistana-PI observaram a presença de $8,0 \%$ do traço falciforme. ${ }^{8,9}$

Apresentamos aqui os resultados de um estudo sobre a frequência de hemoglobinas variantes, no período de dezembro de 2007 a abril de 2008, em mil doadores voluntários de sangue do Centro de Hematologia e Hemoterapia do Piauí - Hemopi. Os sujeitos da pesquisa concordaram em participar do presente estudo, previamente aprovado no Comitê de Ética em Pesquisa da Faculdade Novafapi, sob o número 0176.0.043.000-07.

As amostras foram coletadas, de forma aleatória, em tubos de $5 \mathrm{~mL}$ contendo EDTA, e as análises realizadas por eletroforese em $\mathrm{pH}$ alcalino, usando fitas de acetato de celulose. Foram submetidas à eletroforese em $\mathrm{pH}$ ácido, para diferenciação de hemoglobinas que correm em posições similares. Os testes foram realizados sob corrente elétrica de 300w. A confirmação dos testes foi por análise molecular. ${ }^{10}$

Das mil amostras analisadas, $3,9 \%$ apresentaram o traço falciforme, sendo $3,4 \%$ na forma AS e $0,5 \%$ na forma AC (Figura 1 ), confirmando uma variação de $2 \%$ da prevalência média de portadores do traço falciforme no Brasil, que pode aumentar de acordo com a região e a etnia da população analisada. ${ }^{11}$ Estudos realizados em doadores de Pernambuco (Hemope) evidenciaram 3\% do traço falciforme. ${ }^{12}$ No Rio Grande do Norte, a prevalência foi de $2,22 \%$ do traço falciforme em 630 doadores..$^{13} \mathrm{O}$ traço falciforme no Brasil é uma característica genética levando-se em conta a grande miscigenação e a significativa presença da população afrodescendente. ${ }^{14}$

O estado do Piauí, berço dos primeiros indícios de vida nas Américas, apresenta-se, segundo o censo IBGE 2000, como o quarto estado com população negra autodeclarada, dispondo de poucos indicadores relativos à herança genética da hemoglobina S. Apresentamos nestas breves e significativas notas o estudo das hemoglobinas no estado do Piauí, contribuindo para a educação em saúde dos doadores do Hemopi frente aos aspectos da herança genética da hemo- 


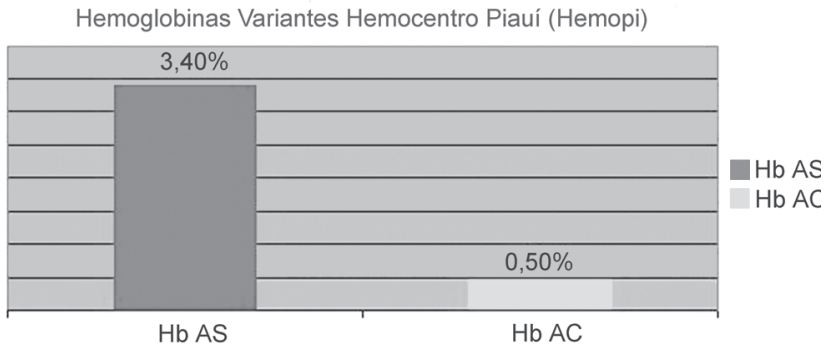

Gráfico

globina S, proporcionando um passo importante na desmistificação do traço falciforme e a compreensão do que seja a doença falciforme, relevante questão de saúde pública.

Levando-se em consideração a elevada presença da população negra no estado do Piauí, as reivindicações dos movimentos sociais organizados e a sensibilidade dos gestores do SUS, os presentes dados visam apresentar à comunidade acadêmica índices de uma questão de saúde pública, a doença falciforme, e asim fornecer subsídios para a implantação do Programa Estadual da Doença Falciforme no estado do Piauí.

\section{Abstract}

The most highly prevalent inherited disease in Brazil and in the world, sickle cell anemia, is considered a public health problem. Characterized by homozygosis for the hemoglobin S gene, the individual has a range of signs and symptoms that require careful treatment. The sickle cell trait is characterized by heterozygosis for the hemoglobin $S$ gene, however the carrier does not express the disease. In the current study we aimed at verifying the presence of the sickle cell trait in 1000 blood donors of the Hematology and Hemotherapy Center of the State of Piaui (Hemopi) in the period from October 2007 to April 2008. After analysis by alkaline and acid electrophoresis, positive cases were confirmed by molecular biology. We obtained rates of $3.4 \%$ for hemoglobin AS and $5 \%$ for hemoglobin $A C$, with a total frequency of $3.9 \%$ in the total of 1,000 blood donors. Rev. Bras. Hematol. Hemoter. 2009;31(6):471-472.

Key words: Hemoglobin S; blood donors; screening; laboratory diagnosis; Hb variants.

\section{Referências Bibliográficas}

1. Brasil, Ministério Da Saúde. Seminário Nacional de Saúde da População Negra. Brasília. 2004.

2. Diniz D, Guedes C. Confidencialidade, aconselhamento genético e saúde pública: um estudo de caso sobre o traço falciforme. Cadernos de Saúde Pública. 2005;21(3):747-55.

3. Cançado RD, Jesus JA. A doença falciforme no Brasil. Rev. Bras. Hematol. Hemoter. 2007;29(3):203-6.

4. Stroncek DF, Rainer C, Sharon V, Byrne KM, Noguchi CT, Klein $\mathrm{HG}$, et al. Sickle $\mathrm{Hb}$ polymerization in RBC components from donors with sickle cell trait prevents effective WBC reduction by filtration. Transfusion. 2002;42(11):1466-472.
5. Oliveira RAG. Hemograma: como fazer e interpretar. São Paulo. Livraria Médica Paulista Editora, 2007.

6. Lobo C, Marra V, Rugan MA. Consenso Brasileiro sobre atividades esportivas e militares e herança falciforme no Brasil - 2007. Rev. Bras. Hematol. Hemoter. 2008;30(6):488-95.

7. Di Nuzzo DVP, Fonseca SF. Anemia falciforme e infecções. Jornal de Pediatria. 2004;80(5):

8. Soares LF, Melo Neto BE, Sà CG. Prevalência do traço falcêmico em alunos do Curso de Farmácia da Universidade Federal do Piauí. Monografia. Curso de especialização em Saúde Pública da Universidade Federal do Piauí. 41p. 2007.

9. Soares LF. II Seminário da Doença Falciforme do Estado do Piauí, Teresina-PI, 2009.

10. Bonini-Domingos CR, Ondei LS, Zamaro PJA. Hemoglobinas similares a S: Um guia prático de identificação. São José do Rio Preto: HN, 2006.

11. Naoum, P. Prevalência e controle da hemoglobina S. Rev. Bras. Hematol. Hemoter. 2000;22(2):142-8.

12. Silva LM, Carvalho MG, Silva RS. Estudos de hemoglobinas humanas realizados na população de Recife. Ciência Cult. 36:851.

Avaliação: Editor e dois revisores externos Conflito de interesse: sem conflito de interesse

Recebido: 17/07/2009

Aceito: 13/08/2009

Universidade Federal do Piaui

Correspondência: Leonardo Ferreira Soares

Rua David Caldas, 1465, Vila Operária

64002-250 - Teresina - PI - Brasil

E-mail:lefs@ufpi.br 